\title{
High strength mortars using ordinary Portland cement-fly ash-fluid catalytic cracking catalyst residue ternary system (OPC/FA/FCC)
}

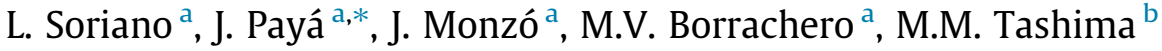 \\ a Instituto de Ciencia y Tecnología del Hormigón, Universitat Politècnica de València, Camino de Vera s/n, Edificio 4G, 46022 Valencia, Spain \\ ${ }^{\mathrm{b}}$ UNESP - Univ Estadual Paulista, Campus de Ilha Solteira, Alameda Bahia, 550, CEP:15385-000 Ilha Solteira, SP, Brazil
}

\section{H I G H L I G H T S}

- An important nucleation effect was attributed to FA at early hydration age.

- An early age pozzolanic effect was developed by FCC.

- High strengths were achieved in binary (OPC/FA) and ternary systems (OPC/FA/FCC).

- Strength contributions (nucleation, hydration, pozzolanic) were calculated.

- The synergic role of the combination of both pozzolans was demonstrated.

\section{A R T I C L E I N F O}

\section{Article history:}

Received 18 August 2015

Received in revised form 10 December 2015

Accepted 16 December 2015

Available online 23 December 2015

\section{Keywords:}

Pozzolan

Fly ash

FCC

High strength mortar

Fixed hydrated lime

\begin{abstract}
A B S T R A C T
The use of ternary systems composed of ordinary Portland cement (OPC) and two pozzolanic mineral admixtures could supply several advantages in terms of the properties in both fresh and hardened states. Fly ash (FA) and spent fluid catalytic cracking catalyst (FCC) were combined to produce high strength mortars due to a synergic effect. OPC/FA systems (70\%/30\%) and OPC/FA/FCC systems (70\%/20\%/10\%) were analyzed by thermogravimetric and SEM techniques. Mortars with different binder/sand ratios were prepared in order to yield high compressive strength values. On the one hand, fly ash particles act as nucleation sites that favour the hydration of Portland cement particles: at early stages ( 7 days), the calculated fixed hydrated lime values were negative, suggestive of a nucleating effect. For a longer curing period (90 days), the pozzolanic effect develops, as can be noted in terms of its compressive strength behaviour. The 90-days curing strength for OPC/FA mortars ranged between 96 and $98 \mathrm{MPa}$. In ternary mixtures (OPC/FA/FCC), FCC act as pozzolan during the initial 7 days period; the presence of fly ash particles favoured the presence of more portlandite by means of the nucleation effect. For longer curing times, fly ash particles also contribute to strength development, producing a synergic effect with FCC. The 90 days curing strength for OPC/FA/FCC mortars ranged between 103 and $106 \mathrm{MPa}$. Binary and ternary mortars reached strength activity index values equal or higher to the unit. Contributions to the strength (i.e. hydration of cement, the nucleation effect, and early and long term pozzolanic effects) have been calculated for 7 and 90 curing days pozzolan-containing mortars.
\end{abstract}

() 2015 Elsevier Ltd. All rights reserved.

\section{Introduction}

High-strength concrete (HSC) is defined as concrete with high compressive strength [1]. Although there is no precise point of separation between high-strength concrete and normal-strength concrete, the American Concrete Institute defined high-strength concrete as that with a compressive strength greater than $6000 \mathrm{psi}$ (about $41.37 \mathrm{MPa}$ ). Usually, this type of concrete is

\footnotetext{
* Corresponding author.

E-mail address: jjpaya@cst.upv.es (J. Payá).
}

produced using a low water/binder ratio, a high quantity of Portland cement (OPC) per cubic metre of concrete, and superplasticiser additives and pozzolanic additions such as silica fume or metakaolin. The Spanish code EHE-08 [2] defines high-strength concrete as concrete with a water/binder ratio lower than 0.4 and with a compressive strength higher than $50 \mathrm{MPa}$ (about $7250 \mathrm{psi})$ for cylindrical specimens $(15 \times 30 \mathrm{~cm})$.

As mentioned above, the use of pozzolanic materials in concrete and mortars, especially in HSC, is becoming common practice. Nowadays, the most widely used pozzolanic materials are industrial by-products, and their use in binder composition can 
contribute to the reduction of OPC consumption, exploitation of raw materials and, consequently, a reduction in the carbon footprint associated with Portland cement-based products. Among the pozzolanic materials, fly ash (FA), metakaolin (MK) and silica fume (SF) are the most used materials [3-8]. The main advantage of using these kinds of material, besides the increment on the mechanical strength, is that they can improve the durability aspects of concrete and mortars such as freeze-thaw resistance, chloride ingress and sulphate attack $[9,10]$.

The mix proportion for HSC is always associated with high consumption of OPC and high-reactive pozzolan (e.g. silica fume) and water/binder ratios lower than 0.3 , a fact that makes the use of a powerful superplasticizer indispensible. The silica fume used for this purpose needs a very small particle diameter in order to promote both the filler and pozzolanic effects, a fact that contributes to the reduction of matrix porosity.

Due the low water/binder ratio used for HSC compared to that of conventional concrete, the amount of portlandite released during Portland cement hydration is reduced and, consequently, the increment on the compressive strength due the pozzolanic reaction is minimised [11-15].

Several papers have reported the use of binary and also ternary systems in the production of HSC. Fly ash is the most widely used pozzolanic material due improvements in workability caused by the sphericity of their particles [16,17]. Moreover, fly ash can also improve mechanical strength and durability aspects of concretes over long term curing ages.

According to multiple studies [18-27], when a low reactivity pozzolan (FA) is used in ternary systems (i.e. OPC plus two mineral admixtures) with another pozzolanic material with high reactivity (SF, MK, etc), a synergic effect between these materials can be observed, it means, the benefits by using both pozzolans are highlighted. The use of FA in ternary systems is justified by its filler effect that acts as a nucleation area for hydrated products produced at early curing ages, increasing the amount of cementing products. Other studies have reported the use of FA in ternary systems for the production of self-compacting concretes. In this case, FA also contributes towards the improvement of fresh concrete workability and the increment of portlandite released due Portland cement hydration to react with high reactive pozzolan [28-31].

Fluid catalytic cracking catalyst residue (FCC) is a waste material generated in the petrochemical industry and several reports have demonstrated that it has excellent properties as a high reactivity pozzolanic material since the initial days of curing [32-39], presenting an efficiency cementing factor (k-factor) higher than the unit [40]. The main disadvantage of FCC is the reduction in the workability of blended concretes and mortars [32]. Hence, the aim of this paper is to assess the production of high-strength mortars using the ternary system Portland cement/fly ash/fluid catalytic cracking catalyst residue (OPC/FA/FCC). Both mechanical and microstructural properties will be assessed.

\section{Experimental program}

Portland cement type CEM I 52.5R (OPC), a fly ash class F fly ash (FA, low calcium content) and spent fluid catalytic cracking catalyst (named as FCC) were all used in the production of high strength mortars based on ternary systems. A polycarboxylate based superplasticizer was used in this study. Table 1 shows the chemical composition for all materials used.
The OPC presented a mean particle diameter of about $20.65 \mu \mathrm{m}$, and $50 \%$ of particles had a diameter lower than $44.09 \mu \mathrm{m}$. Fly ash (FA) was used as-received from the coal power station, presenting a mean particle size of about $25.39 \mu \mathrm{m}$. Otherwise, FCC was dry milled over 20 min in order to reduce its mean particle size to $19.73 \mu \mathrm{m}$, and, consequently, increase its pozzolanic reactivity [28]. Fig. 1 shows the particle size distributions for both FA and FCC mineral admixtures.

The particle morphology of both as-received FA and milled FCC are shown in Fig. 2. FA particles were largely spherical (Fig. 2a), with a wide range of particle diameter. The FCC particles were more irregular, due to the milling process (Fig. $2 \mathrm{~b}$ ).

The following pastes were prepared: Portland cement paste (this control paste was named as p-CON) and two OPC/pozzolan pastes: a paste with $70 \%$ of OPC and $30 \%$ of FA (named p-FA) and a paste containing $70 \%$ of OPC, $20 \%$ FA and $10 \%$ FCC (named p-FA/FCC). All pastes were prepared using a water/binder ratio of 0.27 and in order to obtain a homogeneous mixture, and $0.8 \%$ (with respect to the solid mass) of superplasticiser (SP) was added.

These pastes were placed into cylindrical plastic containers with hermetic closing to avoid any carbonation process, then they were stored at room temperature with $\mathrm{RH} \sim 100 \%$ until the testing age (i.e. 7, 28 and 90 curing days).

In order to stop the hydration process of pastes, paste samples were milled in an agate mortar with acetone. The milled sample was filtered and the collected solid dried off over one hour at $60{ }^{\circ} \mathrm{C}$. Finally, the powder sample was sieved through an $80 \mu \mathrm{m}$ sieve. A Mettler-Toledo TGA 850 equipment was used to characterise the hydrates formed in the curing process and to assess the calcium hydroxide consumption by pozzolans in blended pastes. The test was performed from $35^{\circ} \mathrm{C}$ to $600^{\circ} \mathrm{C}$, using pinholed aluminium sealed crucibles, with a heating rate of $10^{\circ} \mathrm{C} /$ $\mathrm{min}$ in a nitrogen atmosphere of $75 \mathrm{~mL} / \mathrm{min}$.

From the same pastes, fractured samples were prepared for microstructural analysis. For the scanning electron microscopy (SEM, from JEOL JSM6300), fractured samples were recovered with gold and the analysis was performed using the secondary electron mode.

Usually, high strength mortars present higher amounts of OPC than conventional mortars. In order to produce this kind of mortar, we decided to modify the reference mortar from the European standard UNE-EN 196-1:2005 [41] (i.e. $450 \mathrm{~g}$ of OPC and $1350 \mathrm{~g}$ of sand) by adding more OPC. Thus, the cement/sand ratios became: $0.481,0.569$ and 0.667 , and the sum of cement and sand was maintained constant for the control mortars. These mortars with selected cement/sand ratios were obtained by replacing $10 \%, 15 \%$ and $20 \%$ of sand from the standard mortar (cement/sand ratio of 0.333 ) by OPC. Thus, the nomenclature for control mortars was: $10 \%$ (con), $15 \%$ (con) and $20 \%$ (con) (see Table 2).

With respect to the blended mortars produced (Table 2), two classes of binding material were prepared: the first one (binary system OPC/FA) with a proportion of $70 \%$ of Portland cement and 30\% of FA (named 7-3); and the second one (ternary system OPC/FA/FCC) with a proportion of $70 \%$ of Portland cement, $20 \%$ of FA and

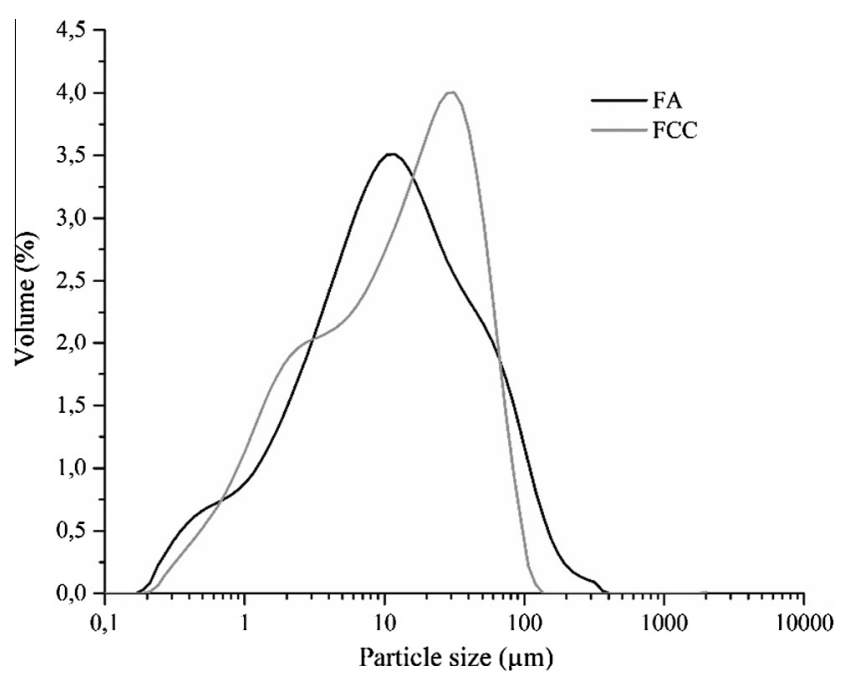

Fig. 1. Particle size distributions for fly ash (FA) and fluid catalytic cracking catalyst residue (FCC).

Table 1

Chemical composition for all used materials (wt\%).

\begin{tabular}{|c|c|c|c|c|c|c|c|c|c|c|}
\hline & $\mathrm{SiO}_{2}$ & $\mathrm{Al}_{2} \mathrm{O}_{3}$ & $\mathrm{Fe}_{2} \mathrm{O}_{3}$ & $\mathrm{CaO}$ & $\mathrm{MgO}$ & $\mathrm{SO}_{3}$ & $\mathrm{~K}_{2} \mathrm{O}$ & $\mathrm{Na}_{2} \mathrm{O}$ & L.O.I & Other \\
\hline FCC & 47.76 & 49.26 & 0.60 & 0.11 & 0.17 & 0.02 & 0.02 & 0.31 & 0.51 & 1.24 \\
\hline FA & 38.85 & 24.52 & 19.63 & 10.52 & 1.20 & 0.47 & 1.17 & 0.22 & 1.56 & 1.86 \\
\hline OPC & 17.42 & 4.30 & 3.30 & 66.17 & 1.45 & 3.33 & 1.21 & 0.46 & 2.35 & 0.01 \\
\hline
\end{tabular}



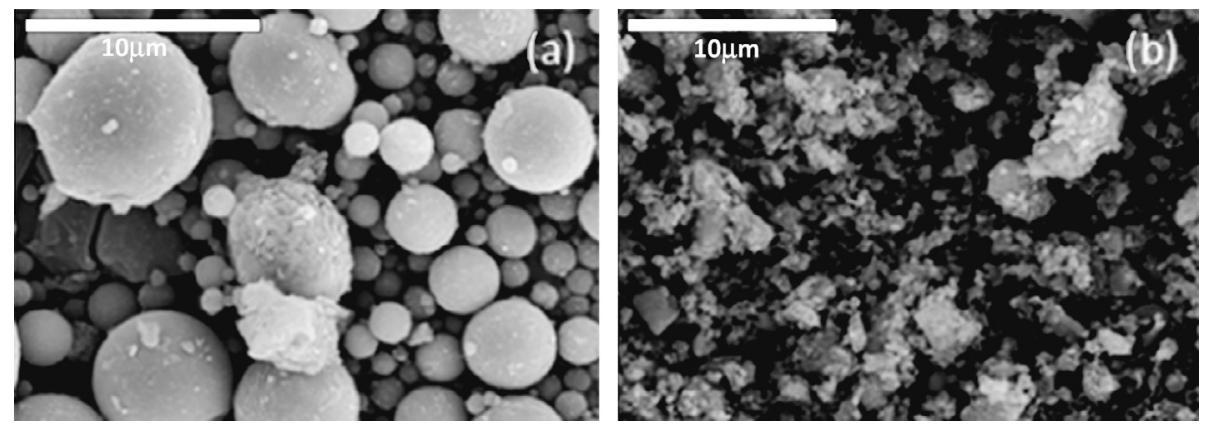

Fig. 2. SEM micrographs: (a) as-received FA; (b) milled FCC.

Table 2

Mix proportions of the mortars ( $\mathrm{SP}=$ superplasticiser).

\begin{tabular}{|c|c|c|c|c|c|c|c|}
\hline & Cement (g) & $\mathrm{FA}(\mathrm{g})$ & FCC (g) & Sand (g) & Water (g) & SP (\%) & Flow table test $(\mathrm{mm})$ \\
\hline 10 (con) & 585.0 & - & - & 1215.0 & 157.9 & 2.5 & 112.5 \\
\hline $10(7-3)$ & 409.5 & 175.5 & - & 1215.0 & 157.9 & 2.0 & 130.0 \\
\hline $10(7-2-1)$ & 409.5 & 117.0 & 58.5 & 1215.0 & 157.9 & 2.5 & 119.5 \\
\hline 15 (con) & 652.5 & - & - & 1147.5 & 176.2 & 1.8 & 125.5 \\
\hline $15(7-3)$ & 456.8 & 195.7 & - & 1147.5 & 176.2 & 1.2 & 125.5 \\
\hline $15(7-2-1)$ & 456.8 & 130.5 & 65.2 & 1147.5 & 176.2 & 2.0 & 132.5 \\
\hline 20 (con) & 720.0 & - & - & 1080.0 & 194.4 & 1.3 & 128.0 \\
\hline $20(7-3)$ & 504.0 & 216.0 & - & 1080.0 & 194.4 & 0.8 & 131.0 \\
\hline $20(7-2-1)$ & 504.0 & 144.0 & 72.0 & 1080.0 & 194.4 & 1.4 & 120.5 \\
\hline
\end{tabular}

Table 3

Percentage of fixed calcium hydroxide $(\% \mathrm{FCH})$, total weight mass loss $\left(\% \mathrm{P}_{\mathrm{T}}\right)$ and mass loss associated with the dehydroxylation of portlandite $\left(\% \mathrm{H}_{\mathrm{CH}}\right)$.

\begin{tabular}{|c|c|c|c|c|c|c|c|c|c|}
\hline & \multicolumn{3}{|c|}{7 days } & \multicolumn{3}{|c|}{28 days } & \multicolumn{3}{|c|}{90 days } \\
\hline & $\% \mathrm{P}_{\mathrm{T}}$ & $\% \mathrm{H}_{\mathrm{CH}}$ & $\% \mathrm{FCH}$ & $\% \mathrm{P}_{\mathrm{T}}$ & $\% \mathrm{H}_{\mathrm{CH}}$ & $\% \mathrm{FCH}$ & $\% \mathrm{P}_{\mathrm{T}}$ & $\% \mathrm{H}_{\mathrm{CH}}$ & $\% \mathrm{FCH}$ \\
\hline p-con & 13.5 & 1.3 & - & 15.1 & 1.4 & - & 16.3 & 1.4 & - \\
\hline $\mathrm{p}-\mathrm{FA}$ & 12.6 & 1.1 & -23.5 & 14.4 & 1.3 & -37.6 & 15.5 & 1.3 & -32.8 \\
\hline p-FA-FCC & 13.2 & 0.7 & 22.0 & 14.8 & 0.7 & 29.1 & 15.3 & 0.6 & 32.7 \\
\hline
\end{tabular}

$10 \%$ of FCC (named 7-2-1: in this case, for three parts of pozzolan, two parts correspond to FA). For all the samples, the water/binder ratio was fixed at 0.27 (the binder being the sum of OPC + FA + FCC). The workability of mortars was performed using a superplasticiser, which was added at a given percentage with respect to the binder (see Table 2). Hence the nomenclature for the prepared mortars is summarised in Table 2: $\mathrm{XX}(\mathrm{YY})$, where $\mathrm{XX}$ represents the percentage of sand replacement $(10 \%, 15 \%, 20 \%)$ and YY represents the composition of binding material ("con" for only OPC binder; "7-3" for FA binary binder; and "7-2-1" for ternary binder).

\section{Results and discussion}

\subsection{Thermogravimetric studies}

Three pastes, with water/binder ratios of 0.27 , were prepared accordingly to the described in the experimental section: a control paste (only OPC as binder, p-con), a fly ash containing paste in $30 \%$ replacement of OPC (p-FA), and a ternary paste with $20 \%$ of FA and $10 \%$ of FCC replacements (p-FA-FCC). The percentage of fixed calcium hydroxide (\%) by pozzolanic reaction was calculated using the obtained data from the thermogravimetric analysis curves, as proposed by Soriano et al. [36]. Table 3 summarises the fixed calcium hydroxide $(\% \mathrm{FCH})$, the total mass loss in the $35-600{ }^{\circ} \mathrm{C}$ range $\left(\mathrm{P}_{\mathrm{T}}, \%\right)$ and the mass loss corresponding to the dehydroxylation of portlandite $\left(\% \mathrm{H}_{\mathrm{CH}}\right)$ in the $520-600{ }^{\circ} \mathrm{C}$ range for all curing ages. In Fig. 3, DTG curves for pastes cured at 7, 28 and 90 days are depicted.

For the control paste, the mass loss associated with the dehydroxylation of portlandite $\left(\% \mathrm{H}_{\mathrm{CH}}\right)$ was very low, if compared with values found in previous studies. Thus, Payá et al. [34] reported $2.90 \%$ for $\% \mathrm{H}_{\mathrm{CH}}$ in 0.5 water/cement ratio at 28 days, and from the results in Soriano et al. [36] a value of $3.20 \%$ was calculated in similar conditions, while the value of $3.43 \%$ was calculated by Pacewska et al. [38]. On the other hand, Payá et al. [34] reported $1.57 \%$ for a paste with a water/cement ratio of 0.25 , which was similar to the value reported here $(1.39 \%)$ at the same curing age (28 days). This behaviour clearly demonstrates the significant dependence on the available water in cement mixtures in terms of portlandite formation. This fact has a crucial role in the pozzolanic processes when a pozzolan is present in the cementing matrix.

Pastes with a low water/binder ratio yielded a decreasing of the Portland cement hydration process rate when compared to pastes with high amount of water [34]. Loukili et al. [14] performed a detailed study in high-performance concretes with a water/binder ratio 0.2 , and silica fume replacing Portland cement in percentage of $24 \%$, yielding a Portland cement hydration rate for a HSC of about 0.58 for 28 curing days.

For all curing ages, p-FA pastes produced negative values of fixed calcium hydroxide (\%FCH). This fact confirmed that fly ash contributes towards accelerating Portland cement hydration (fly ash particles act as nucleation sites for precipitating hydrates from Portland cement). Similar results were found by Wang [42]. This author studied the effect of fly ash on the hydration process for mixtures with low water/binder ratios and with high percentages of FA (over $25 \%$ by volume), concluding that the use of FA accelerates the Portland cement hydration process mainly due the dilu- 
(a)

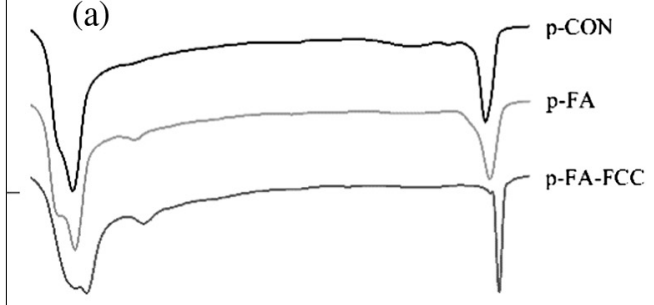

$0.001^{\circ} \mathrm{C}^{-1}$ (b)

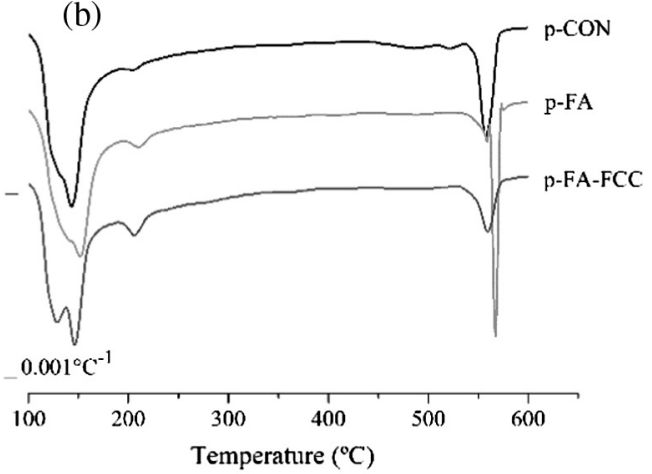

(c)

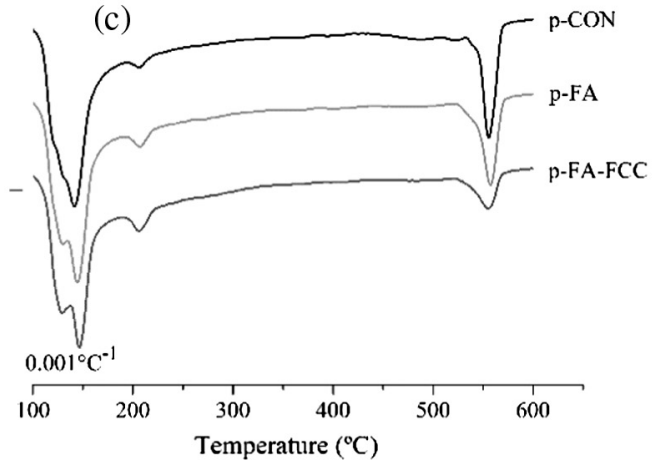

Fig. 3. DTG curves for pastes cured at: (a) 7 curing days; (b) 28 curing days and (c) 90 curing days.

tion effect caused by the use of pozzolan with reduced mean particle diameters.

It is important to state that the improvement on the Portland cement hydration (negative values for \% FCH) does not mean that the pozzolanic reaction did not develop. Thus, as can be observed in Fig. 3, for pastes containing FA, the presence of a defined peak centred in the range $180-240{ }^{\circ} \mathrm{C}$ was observed. This peak corresponds to the dehydration of calcium aluminate and/or calcium aluminosilicate hydrates (CAH and/or $\mathrm{CASH}$ ), typical hydrated products formed due the pozzolanic reaction of silicoaluminous pozzolans. This peak was smaller for the control paste, suggesting that the total quantity of $\mathrm{CAH} / \mathrm{CASH}$ was significantly higher in FA containing paste (p-FA). FA usually reacted at longer curing periods, and this behaviour increased from 28 to 90 days, the fixed lime percentage changed from $-37.6 \%$ to $-32.8 \%$. This reduction in the negative value for \% FCH has been attributed to the pozzolanic reactivity of $\mathrm{FA}$, which becomes a more important process than the hydration of Portland cement (developed mainly in the first 28 days).

Otherwise, when FCC is present in the paste (p-FA-FCC paste), positive values for fixed calcium hydroxide were obtained even for pastes cured during 7 days. For p-FA-FCC paste, the fixed calcium hydroxide was increased for longer curing days. In this case, FCC acts as a high reactivity pozzolanic material, reacting with calcium hydroxide released during Portland cement hydration during the initial curing days. It can be confirmed by the presence of a peak associated with the decomposition/dehydration of CAH and/ or CASH (temperature range $180-240^{\circ} \mathrm{C}$ ): in Fig. 3a the peak in this zone was significantly larger than those found in p-con paste and in p-FA paste at 7 days of curing.

For ternary pastes, the combined effect of FA and FCC promotes a good development of the hydration reactions: FA contributes to the Portland cement hydration, and consequently to the increment on the amount of calcium hydroxide released (portlandite), and FCC reacts with calcium hydroxide in order to form additional products from pozzolanic reaction.

\subsection{Scanning electron microscopy studies}

Fractured paste samples were assessed by scanning electron microscopy (SEM) in order to study the hydration products formed in each paste produced. SEM micrographs for p-FA pastes are shown in Fig. 4, and for p-FA-FCC pastes in Fig. 5.

Fig. $4 \mathrm{a}$ and $4 \mathrm{~b}$ show an OPC/FA paste cured for 7 days, where the spherical particles of FA can be observed, and they were only slightly recovered by hydration products. Fig. $4 \mathrm{c}$ and d show some FA particles in the cementing matrix that were reacted after 90 days of curing and covered by hydration products: the attack on the FA particles was evident and some of them were fully covered by cementitious products and also were partially dissolved.

Fig. 5a and b show that many FA particles were not reacted after the 7 days curing period. Fig. $5 c$ shows a typical product formed from FCC pozzolanic reaction (stratlingite), indicating that an early pozzolanic reaction took place after 7 days of curing. In Fig. $5 d-f$ (90 days curing time), an important group of FA particles was significantly reacted, which indicated that the pozzolanic reaction progress took place for long curing time, despite a significant part of portlandite already having reacted at an early age into FCC particles.

\subsection{Mechanical strength studies}

Selected mortars were prepared accordingly to the mix proportions given in Table 2. An increment on the sand replacement by binder (from $10 \%$ to $20 \%$ ) reduces the required amount of superplasticiser in mortars for yielding similar workability. This behaviour is due to the increase in the fine particles/sand ratio.

Table 4 summarises the flexural $\left(R_{f}\right)$ and compressive $\left(R_{c}\right)$ strengths of high strength mortars tested at 7, 28 and 90 curing days. In general terms, the increase in the binding material content results in a modest increase in the compressive strength of mortars, over all curing ages. This behaviour was due probably to the enhancement of the matrix and the interfacial zone by means of 

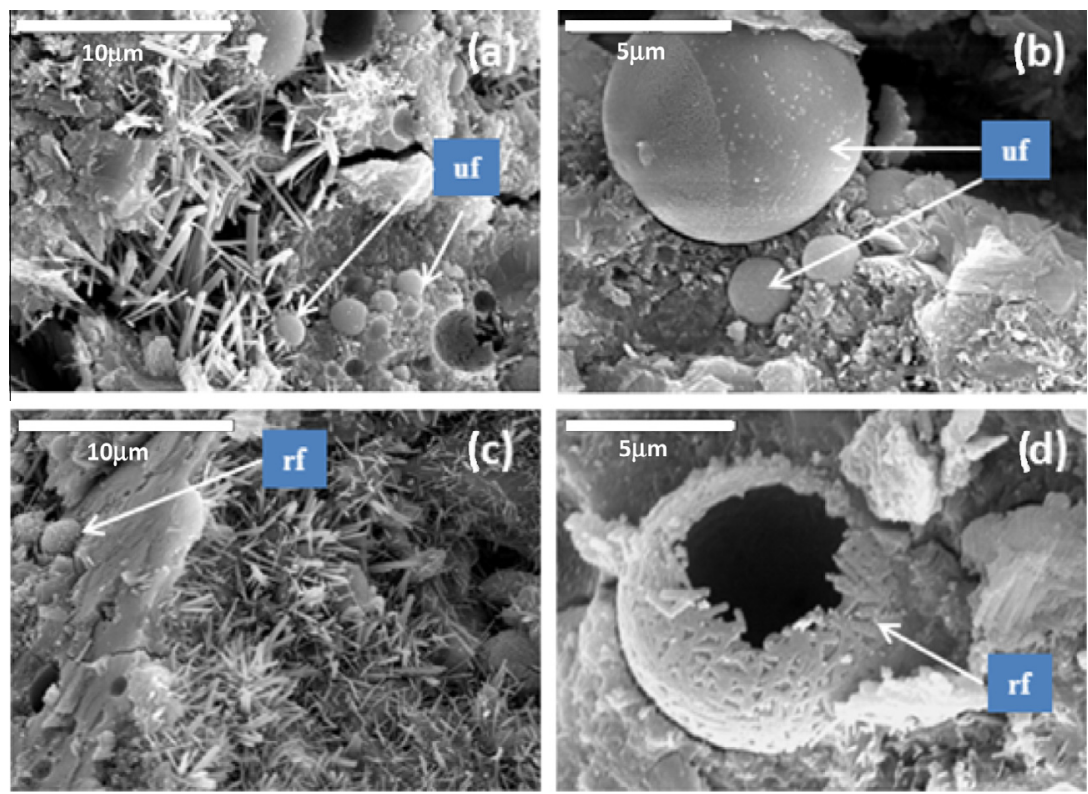

Fig. 4. SEM micrographs for p-7-3 paste (OPC/FA) at different curing ages: (a) and (b) 7 days; (c) and (d) 90 days. (key: uf: unreacted fly ash; rf: reacted fly ash).
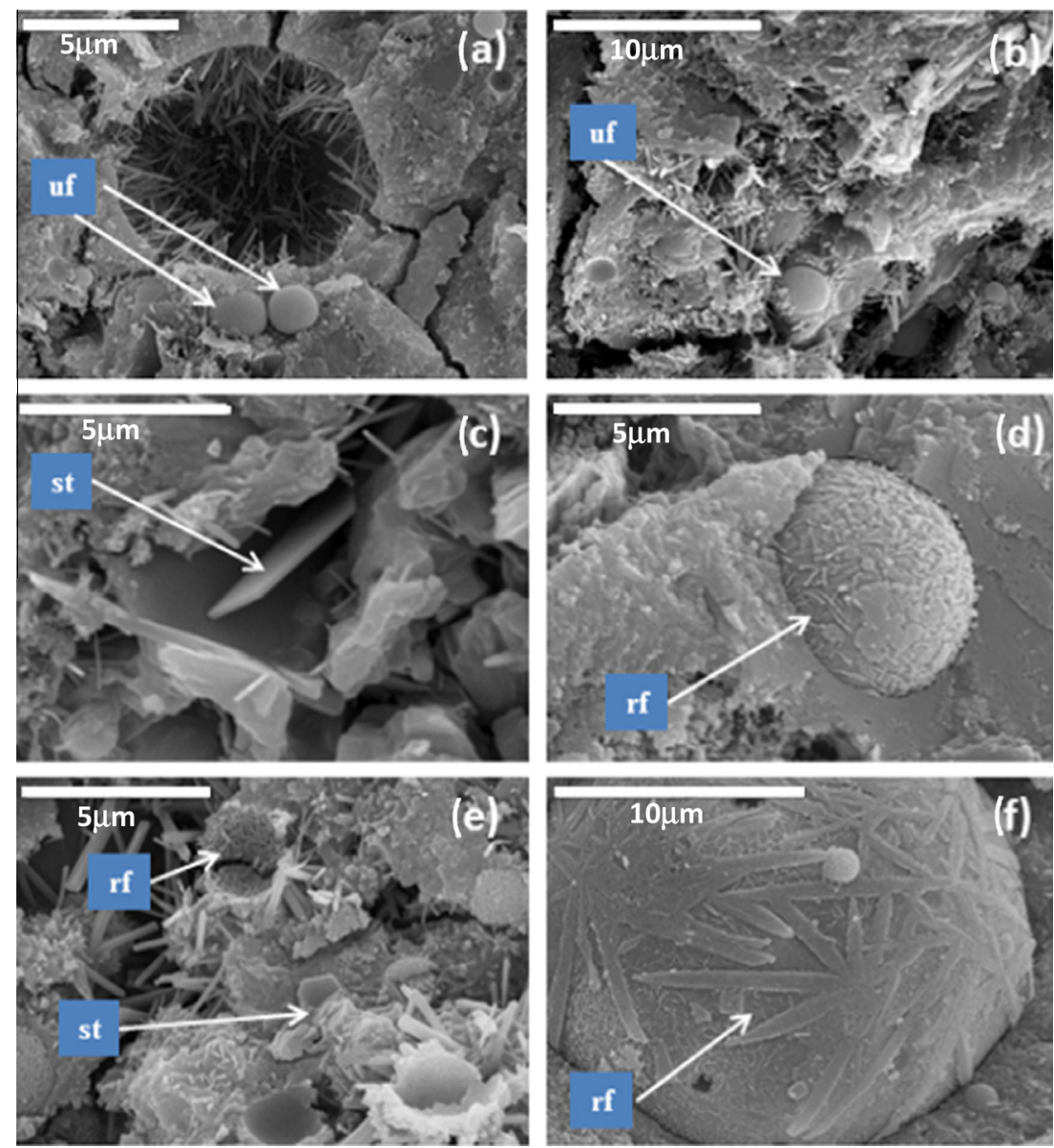

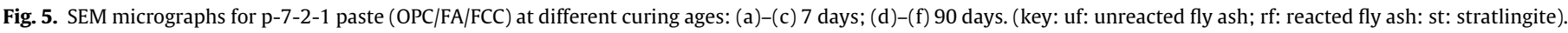

the increasing amount of fine particles. And, as expected, $R_{c}$ values increased with curing time for all prepared mortars.

A comparison of control mortars, 10\% (con), 15\% (con) and 20\% (con), with the corresponding mortars with FA, 10 (7-3), 15 (7-3) and 20 (7-3), shows that for earlier curing ages (7 and 28 days) $R_{c}$ values for control mortars were higher than those found for FA mortars. These means that, despite the presence of fly ash particles that favoured the hydration of Portland cement particles, the 
Table 4

Flexural $\left(R_{f}, \mathrm{MPa}\right)$ and compressive $\left(R_{c}, \mathrm{MPa}\right)$ strengths of mortars.

\begin{tabular}{llrr}
\hline & 7 days & 28 days & \multicolumn{1}{c}{90 days } \\
\hline Flexural & & & \\
$10($ con $)$ & $12.7 \pm 0.6$ & $14.6 \pm 0.4$ & $14.9 \pm 0.8$ \\
$10(7-3)$ & $10.7 \pm 0.2$ & $14.1 \pm 0.8$ & $13.1 \pm 0.6$ \\
$10(7-2-1)$ & $13.1 \pm 1.0$ & $14.1 \pm 0.6$ & $11.9 \pm 0.4$ \\
$15($ con $)$ & $14.5 \pm 0.8$ & $15.8 \pm 0.7$ & $14.5 \pm 1.9$ \\
$15(7-3)$ & $11.5 \pm 0.4$ & $14.9 \pm 0.8$ & $13.3 \pm 0.8$ \\
$15(7-2-1)$ & $13.2 \pm 0.7$ & $14.7 \pm 0.2$ & $12.1 \pm 0.4$ \\
$20($ con $)$ & $14.7 \pm 0.3$ & $16.2 \pm 1.4$ & $14.3 \pm 1.2$ \\
$20(7-3)$ & $12.2 \pm 1.1$ & $14.7 \pm 0.4$ & $14.1 \pm 1.0$ \\
$20(7-2-1)$ & $13.6 \pm 0.6$ & $15.6 \pm 0.3$ & $13.5 \pm 1.2$ \\
Compressive & & & \\
$10($ con $)$ & $66.0 \pm 0.9$ & $80.9 \pm 2.9$ & $92.1 \pm 1.3$ \\
$10(7-3)$ & $59.6 \pm 1.4$ & $79.3 \pm 1.8$ & $96.9 \pm 3.1$ \\
$10(7-2-1)$ & $74.2 \pm 3.8$ & $92.8 \pm 3.5$ & $103.2 \pm 3.5$ \\
$15($ con $)$ & $70.6 \pm 3.6$ & $83.7 \pm 3.8$ & $96.9 \pm 1.1$ \\
$15(7-3)$ & $61.1 \pm 2.9$ & $80.2 \pm 1.1$ & $96.8 \pm 2.4$ \\
$15(7-2-1)$ & $78.7 \pm 2.6$ & $97.3 \pm 4.0$ & $105.6 \pm 1.0$ \\
$20($ con) & $72.9 \pm 3.9$ & $85.4 \pm 2.6$ & $95.2 \pm 2.8$ \\
$20(7-3)$ & $64.4 \pm 2.3$ & $81.1 \pm 2.1$ & $97.5 \pm 3.7$ \\
$20(7-2-1)$ & $75.8 \pm 4.1$ & $95.7 \pm 4.2$ & $104.2 \pm 3.6$ \\
\hline
\end{tabular}

strength gain did not compensate the relative reduction in the content of OPC. However, due to the long-term reactivity for fly ash particles, at 90 days of curing, equal or higher $R_{c}$ values for FA containing mortars were obtained. This is the typical pozzolanic contribution of fly ash in Portland cement binders. For 90 day curing time, the compressive strength of control mortars ranged from 92.1 to $96.9 \mathrm{MPa}$ while for FA containing mortars the range was 96.8-97.5 MPa. For the longest curing time studied, the pozzolanic contribution of FA particles plus the increasing in the hydration of OPC particles let to compensate the reduction of $30 \%$ of the Portland cement content. A similar trend was found for flexural strength development: thus, at 7 days curing time, the control mortar ranged from 12.7 to $14.7 \mathrm{MPa}$, while for FA containing mortar the range was $10.7-12.2 \mathrm{MPa}$. For the 90 days curing time, strengths increased, reaching values greater than $13 \mathrm{MPa}$ for both types of mixtures.

Blended binders containing FA and FCC, 10 (7-2-1), 15/7-2-1) and 20 (7-2-1), presented the highest $R_{c}$ values for all mix proportions and curing times compared to their respective control ones. The high reactivity at early age of FCC came in spite of the reduction of the Portland cement content in the ternary mixtures $(30 \%$ less than in the control mix), and the low reactivity of fly ash (as can be seen before in the FA containing mixes), the presence of $10 \%$ of FCC enhanced significantly the development of strength at 7 days. This trend is maintained for 28 days of curing, and 10$13 \mathrm{MPa}$ greater $R_{c}$ values were found for ternary mortars respect to the control ones. Finally, at 90 days of curing, the contribution of FA in these mortars produced $R_{c}$ values greater than $100 \mathrm{MPa}$, significantly higher than those found for the control mortars.

In order to assess the contribution of pozzolanic materials on the compressive strength of mortars, the strength activity index was determined. This index is defined as the ratio between the strength of the blended mortar and the strength of control mortar [43]. Fig. 6 shows the strength activity index for all tested blended mortars.

The strength activity index for FA blended mortars increased with curing time, yielding the best behaviour for the mixture 10 (7-3). The obtained data confirms that FA is a pozzolanic material that reacts for long curing times, i.e. after 28 curing days. However, due to the contribution (nucleation effect) of FA particles on the hydration of OPC particles, strength activity index values at 7 days curing time fell in the range of 0.85-0.90, indicating the important role that FA particles played in these systems.
For FA-FCC blended mortars, for all proportions and for all curing ages the strength activity index was higher than those obtained for FA containing mortars. The results demonstrated the effectiveness of the ternary systems both at early and at long term curing ages because strength activity index values were higher than the unit.

In order to assess the contribution of both pozzolans in a ternary OPC/FA/FCC system, the following approach has been developed in terms of compressive strength. The control mortar has a $\left(R^{t}\right)_{\text {OPC }}$ strength at a given curing time " $t$ ". One can consider that the strength is proportional to the relative cement content $(C)$ with respect to the control mortar as follows:

$\left(R^{t}\right)_{c}=\left(R^{t}\right)_{O P C} * C$,

where $\left(R^{t}\right)_{\text {OPC }}$ is the strength of the control mortar, $C$ is the relative amount of cement in the pozzolan containing mortar and $\left(R^{t}\right)_{c}$ is the strength contribution of the cement hydration in pozzolan containing mortar. Thus, in our case, in which the replacement of OPC was $30 \%$, then $C$ is equal to 0.7 , and then $\left(R^{t}\right)_{c}$ corresponds to the contribution to the strength due to the relative amount of cement at a given curing time " $t$ ". $\left(R^{t}\right)_{c}$ values for 7 and 90 days curing times were calculated and are summarised in Table 5. For 10-con, 20con and 30-con mortars, $\left(R^{7 d}\right)_{c}$ were in the range 46.2-51.3 MPa, with a mean value of $44.88 \mathrm{MPa}$. In the same way, $\left(R^{90 d}\right)_{c}$ fell in the range 64.47-67.83 $\mathrm{MPa}$, with a mean value of $66.31 \mathrm{MPa}$.

The compressive strength of a fly ash blended cement (OPC/FA) system is calculated as follows:

$\left(R^{t}\right)_{F A}=\left(R^{t}\right)_{c}+\left(R^{t}\right)_{F A, p}$,

where $\left(R^{t}\right)_{F A}$ is the compressive strength of mortar prepared with the blended cement and $\left(R^{t}\right)_{F A, p}$ is the pozzolanic contribution to the strength. However, at early ages, fly ash particles do not demonstrate a pozzolanic reaction, and consequently the second term in Eq. (2) would be negligible. Early age strengths ( 7 days curing time; see Table 4) for OPC/FA systems were significantly higher than corresponding $\left(R^{7 d}\right)_{c}$ values (see Table 5 ). This behaviour means that there is a nucleation effect and hydration of Portland cement particles is favored in the presence of FA particles. Thus, Eq. (2) must be transformed into:

$\left(R^{7 d}\right)_{F A}=\left(R^{7 d}\right)_{c}+\left(R^{7 d}\right)_{F A, n}$,

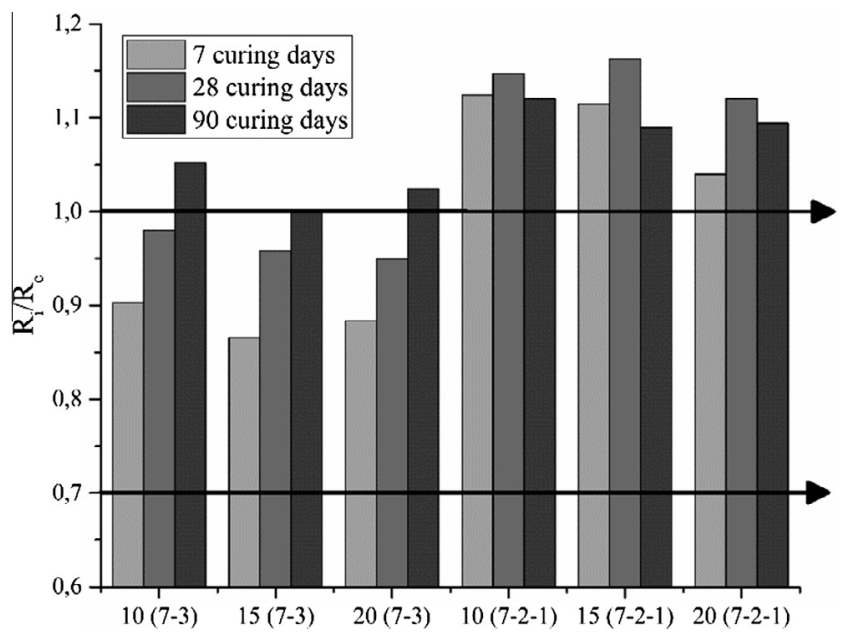

Fig. 6. Calculated strength activity index for mortars with pozzolanic admixtures. 
Table 5

Calculated strength (in MPa) terms from Eqs. (1)-(6).

\begin{tabular}{|c|c|c|c|c|c|c|c|}
\hline Mortar dosage & $\left(R^{7 d}\right)_{c}$ & $\left(R^{90 d}\right)_{c}$ & $\left(R^{7 \mathrm{~d}}\right)_{F A, n}$ & $\left(R^{90 d}\right)_{F A, p}$ & $\left(R^{7 d}\right)_{F C C, p}$ & $\left(R^{90 d}\right)_{F C C, t}$ & $\left(R^{90 d}\right)_{F C C, e}$ \\
\hline $10 \%$ & 46.20 & 64.47 & 13.40 & 19.03 & 19.07 & 105.16 & 103.20 \\
\hline $15 \%$ & 49.42 & 67.83 & 11.68 & 17.29 & 21.49 & 108.64 & 105.60 \\
\hline $20 \%$ & 51.03 & 66.64 & 13.37 & 17.49 & 15.86 & 103.07 & 104.20 \\
\hline Mean values & 48.88 & 66.31 & 12.82 & 17.94 & 18.81 & 105.62 & 104.33 \\
\hline
\end{tabular}

where $\left(R^{7 d}\right)_{F A, n}$ is the contribution to the strength attributed to the nucleation effect. These values (see Table 5) ranged from 11.68 to 13.40 MPa, with a mean value of $12.82 \mathrm{MPa}$. This contribution enhanced the production of portlandite, which would be available for pozzolan reaction at longer curing times, or, in the case of the presence of an additional high reactive pozzolan, would have been reacted at early curing times.

At long curing times (e.g. 90 days), fly ash particles have been partially reacted as showed in SEM studies, meaning that there is a pozzolanic contribution. Thus, the compressive strength at 90 days for OPC/FA mortars, $\left(R^{90 d}\right)_{F A}$, is calculated as follows:

$\left(R^{90 d}\right)_{F A}=\left(R^{90 d}\right)_{c}+\left(R^{7 d}\right)_{F A, n}+\left(R^{90 d}\right)_{F A, p}$,

where $\left(R^{90 d}\right)_{F A, p}$ is the pozzolanic contribution at long term from the fly ash. These calculated values fell in the range of 17.29-19.03 MPa (see Table 5), and the mean value was $19.94 \mathrm{MPa}$.

With respect to the ternary system OPC/FA/FCC, the compressive strength at 7 days would be calculated taking into account that the contribution due to nucleation effect for fly ash is now proportional to the relative pozzolan content (2/3 in our case: for 3 parts of pozzolan, 2 parts correspond to the fly ash). Additionally, the pozzolanic contribution of fly ash would be negligible, $\left(R^{7 d}\right)_{F A, n} \cong 0$, and FCC particles would have a negligible nucleation effect because they are rapidly covered by pozzolanic reaction products according to previous SEM results, $\left(R^{7 d}\right)_{F C C, n} \cong 0$. Thus, the $\left(R^{7 d}\right)_{F C C}$ can be calculated as follows:

$\left(R^{7 d}\right)_{F C C}=\left(R^{7 d}\right)_{c}+\frac{2}{3}\left(R^{7 d}\right)_{F A, n}+\left(R^{7 d}\right)_{F C C, p}$

where $\left(R^{7 d}\right)_{F C C, p}$ represents the pozzolanic contribution of FCC in the system. The values related to the pozzolanic contribution of FCC ranged from 15.86 to $21.49 \mathrm{MPa}$, with a mean value of $18.81 \mathrm{MPa}$ (see Table 5).

Finally, the strength for OPC/FA/FCC mixtures at 90 days curing time would be calculated as follows, taking into account the early age pozzolanic contribution from FCC, $\left(R^{7 d}\right)_{F C C, p}$, and the long term pozzolanic contribution from FA, 2/3 the value of the OPC/FA system, $\left(R^{90 d}\right)_{F A, p}$ :

$\left(R^{90 d}\right)_{F C C, t}=\left(R^{90 d}\right)_{c}+\frac{2}{3}\left(R^{7 d}\right)_{F A, n}+\left(R^{7 d}\right)_{F C C, p}+\frac{2}{3}\left(R^{90 d}\right)_{F A, p}$,

where $\left(R^{90 d}\right)_{\mathrm{FCC}, t}$ is the theoretical value calculated from Eq. (6). Experimental strength values for OPC/FA/FCC system at 90 days curing time, $\left(R^{90 d}\right)_{\mathrm{FCC}, e}$, were in the range of $103.2-105.6 \mathrm{MPa}$ (Table 4), with a mean value of $104.33 \mathrm{MPa}$. Theoretical values, $\left(R^{90 d}\right)_{\mathrm{FCC}, t}$, were in a similar strength range, 103.7-108.64 MPa, with a mean value of $105.62 \mathrm{MPa}$. The theoretical mean value was very similar to the experimental one (105.62 MPa vs $104.33 \mathrm{MPa}$ ), meaning that our approach proposed is consistent.

Fig. 7 shows the different contributions to the strength for OPC/FA and OPC/FA/FCC systems at 7 and 90 curing days. The pozzolanic contribution of FCC at 7 days of curing was very important due to the nucleation effect of FA particles, which increased the

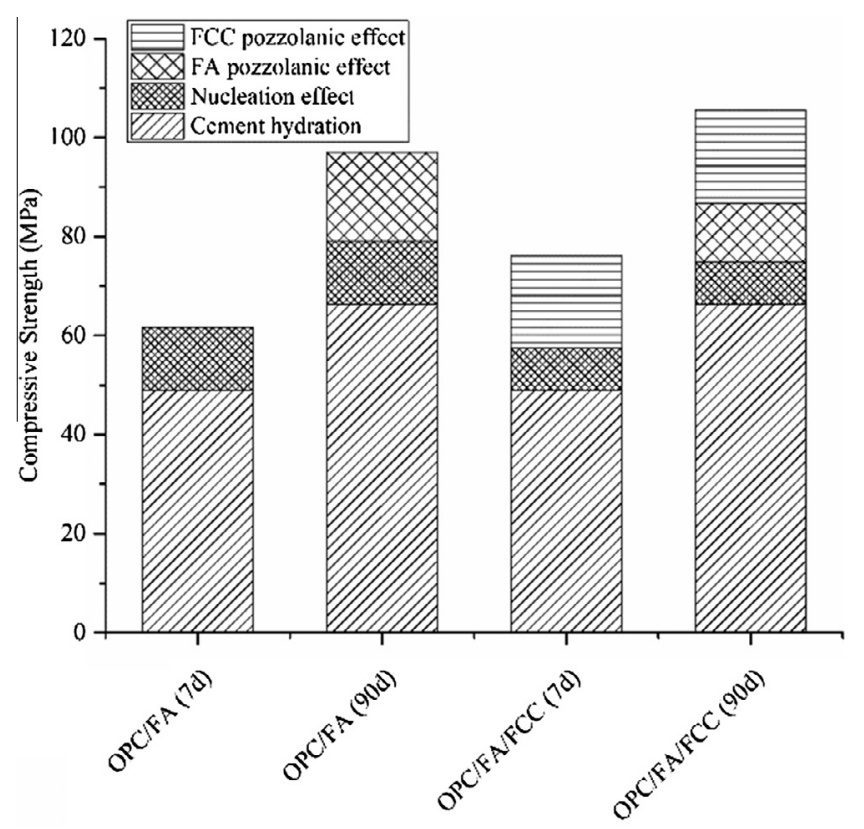

Fig. 7. Compressive strength contributions for $\mathrm{OPC} / \mathrm{FA}$ and $\mathrm{OPC} / \mathrm{FA} / \mathrm{FCC}$ systems calculated for 7 and 90 days curing times.

amount of available portlandite. For the longest curing time (90 days), the pozzolanic contribution of FA particles was also significant. This provides evidence of the synergic role of the combination of both pozzolans in the same mixture where each pozzolanic material presents its pozzolanic contribution but, in the same way, the presence of FA particles contributes to the enhancement of the nucleation effect thus favoring the pozzolanic reactivity of FCC for early curing ages.

\section{Conclusions}

High-strength mortars were designed using OPC, FA and FCC. Achieving this high strength was carried out by means of low water/binder ratios of 0.27 . In these conditions, the following conclusions can be stated in terms of microstructure and mechanical properties:

Thermogravimetric data showed that the main role of fly ash particles in an OPC/FA system is the nucleation effect, yielding negative values for the hydrated lime fixation. This effect is related to the excellent strength development at early and long term curing ages in OPC/FA mortars. FA-containing mortars had a pozzolanic contribution for long term ages (i.e. 90 days). SEM studies confirm qualitatively the degree of pozzolanic reaction of FA particles with curing time.

At early stages, the nucleation effect of fly ashes produced a higher quantity of portlandite from OPC hydration: this behaviour has a decisive influence on the pozzolanic role of FCC in the OPC/ FA/FCC systems. A high percentage of hydrated lime fixation was found, due to the synergic effect at an early age. FCC produced a 
very important strength contribution, which is attributed to the pozzolanic reaction.

Despite to the consumption of portlandite at an early age in the OPC/FA/FCC system, unreacted FA particles also play an important role over longer curing times. In this way, an important contribution to the strength was developed by FA.

The combination of both pozzolans led to a synergic effect, which has been elucidated by the production of high-strength mortars with a reduction of $30 \%$ of the ordinary Portland cement content.

\section{Acknowledgement}

This work was supported by Ministerio de Ciencia y Tecnología, Spain (Project MAT 2001-2694). Thanks are given to the Electron Microscopy Service of the Universitat Politècnica de València.

\section{References}

[1] P.K. Metha, P.J.M. Monteiro, Concrete: Microstructure, Properties and Materials, McGraw-Hill, New York, 2006.

[2] EHE-08, Instrucción de hormigón estructural (EHE-08), Real Decreto 1247/ 2008, B.O.E. no 203, 2008.08.22, Spain.

[3] M.D.A. Thomas, M.H. Shehata, S.G. Shashiprakash, D.S. Hopkins, K. Cail, Use of ternary cementitious systems containing silica fume and fly ash in concrete, Cem. Concr. Res. 29 (1999) 1207-1214.

[4] T.K. Erdem, O. Kirca, Use of binary and ternary blends in high strength concrete, Constr. Build. Mater. 22 (2008) 1477-1483.

[5] M.A. Elrahman, B. Hillemeir, Combined effect of fine fly ash and packing density on the properties of high performance concrete: an experimental approach, Constr. Build. Mater. 58 (2014) 225-233.

[6] A. Elahi, P.A.M. Basheer, S.V. Nanukuttan, Q.U.Z. Khan, Mechanical and durability properties of high performance concretes containing supplementary cementitious materials, Constr. Build. Mater. 24 (2010) 292299.

[7] P. Dinakar, S.N. Manu, Concrete mix design for high strength self compacting concrete using metakaolin, Mater. Des. 60 (2014) 661-668.

[8] A.F. Bingöl, I. Tohumcu, Effects of different regimes on the compressive strength properties of self compacting concrete incorporating fly ash and silica fume, Mater. Des. 51 (2013) 12-18.

[9] G. Peiwei, D. Min, F. Naiqian, The influence of superplasticizer and superfine mineral powder on the flexibility, strength and durability of HPC, Cem. Concr. Res. 31 (2001) 703-706.

[10] M.H. Shehata, M.D.A. Thomas, Use of ternary blends containing fly ash to suppress expansion due to alkali-silica reaction in concrete, Cem. Concr. Res. 32 (2002) 341-349.

[11] E. Ghafari, H. Costa, E. Júlio, A. Portugal, L. Durães, The effect of nanosilica addition on flowability, strength and transport properties of ultra high performance concrete, Mater. Des. 59 (2014) 1-9.

[12] T. Oertel, U. Helbig, F. Hutter, H. Kletti, G. Sextl, Influence of amorphous silica on the hydration in ultra-high performance concrete, Cem. Concr. Res. 58 (2014) 121-130.

[13] T. Oertel, F. Hutter, U. Helbig, G. Sextl, Amorphous silica in ultra-high performance concrete: first hour of hydration, Cem. Concr. Res. 58 (2014) $131-142$.

[14] A. Loukili, A. Khelidj, P. Richard, Hydration kinetics, change of relative humidity, and autogenous shrinkage of ultra-high-strength concrete, Cem. Concr. Res. 29 (1999) 577-584.

[15] S. Zhao, W. Sun, Nano-mechanical behaviour of a green ultra-high performance concrete, Constr. Build. Mater. 63 (2014) 150-160.

[16] Y. Li, A.K.H. Kwan, Ternary blending of cement with fly ash microsphere and condensed silica fume to improve the performance of mortar, Cem. Concr. Compos. 49 (2014) 26-35.

[17] A.K.H. Kwan, Effects of fly ash microsphere on rheology, adhesiveness and strength of mortar, Constr. Build. Mater. 42 (2013) 137-145.

[18] G.C. Isaia, A.L.G. Gastaldino, R. Moraes, Physical and pozzolanic action of mineral additions on the mechanical strength of high-performance concrete Cem. Concr. Compos. 25 (2003) 69-76.
[19] P.K. Metha, P.C. Aitci, Principles underlying production of high-performance concrete, Cem. Concr. Aggr. 12 (1990) 70-80.

[20] S. Antiohos, K. Maganari, S. Tsimas, Evaluation of blends of high and low calcium fly ashes for use as supplementary cementing materials, Cem. Concr. Compos. 27 (2005) 349-356.

[21] W. Dehuai, C. Zhaoyuan, On predicting compressive strengths of mortars with ternary blends of cement, GGBFS and fly ash, Cem. Concr. Res. 27 (1997) 487493.

[22] Z. Wu, T.R. Naik, Properties of concrete produced from multicomponent blended cements, Cem. Concr. Res. 32 (2002) 1937-1942.

[23] J. Bai, S. Wild, B.B. Sabir, Chloride ingress and strength loss in concrete with different PC-PFA-MK binder compositions exposed to synthetic seawater, Cem. Concr. Res. 33 (2003) 353-362.

[24] M.I. Khan, C.J. Lynsdale, P. Waldron, Porosity and strength of PFA/SF/OPC ternary blended paste, Cem. Concr. Res. 30 (2000) 1225-1229.

[25] S.A. Barbhuiya, J.K. Gbagbo, M.I. Russell, P.A.M. Basheer, Properties of fly ash concretes modified with hydrated lime and silica fume, Constr. Build. Mater. 23 (2009) 3233-3239.

[26] W. Wongkeo, P. Thongsanitgarn, A. Chaipanich, Compressive strength and dry shrinkage of fly ash-bottom ash-silica fume multi-blended cement mortars, Mater. Des. 36 (2012) 655-662.

[27] W. Wongkeo, P. Thongsanitgarn, A. Ngamjarurojana, A. Chaipanich, Compressive strength and chloride resistance of self-compacting concrete containing high level fly ash and silica fume, Mater. Des. 64 (2014) 261-269.

[28] K. Turk, Viscosity and hardened properties of self-compacting mortars with binary and ternary cementitious blends of fly ash and silica fume, Constr. Build. Mater. 37 (2012) 3226-3234.

[29] M. Sagmaram, H.A. Christiano, I.O. Yaman, The effect of chemical admixtures and mineral additives on the properties of self-compacting mortars, Cem. Concr. Compos. 28 (2006) 432-440.

[30] M. Nehdi, M. Pardhan, S. Koshowski, Durability of self-consolidating concrete incorporating high-volume replacement composite cements, Cem. Concr. Res. 34 (2004) 2103-2112.

[31] E. Güneyisi, M. Gesoğlu, E. Özbay, Strength and drying shrinkage properties of self-compacting concretes incorporating multi-system blended mineral admixtures, Constr. Build. Mater. 24 (2010) 1878-1887.

[32] J. Payá, J. Monzó, M.V. Borrachero, Fluid catalytic cracking catalyst residue (FC3R). An excellent mineral by-product for improving early strength development of cement mixtures, Cem. Concr. Res. 29 (1999) 1773-1779.

[33] J. Payá, J. Monzó, M.V. Borrachero, S. Velázquez, The chemical activation of pozzolanic reaction of fluid catalytic cracking catalyst residue (FC3R) in lime pastes, Adv. Cem. Res. 19 (2007) 9-16.

[34] J. Payá, J. Monzó, M.V. Borrachero, S. Velázquez, Evaluation of the pozzolanic activity of fluid catalytic cracking catalyst residue (FC3R). Thermogravimetric analysis studies on FC3R-Portland cement pastes, Cem. Concr. Res. 33 (2003) 603-609.

[35] M. García de Lomas, M.I. Sánchez de Rojas, M. Frías, Pozzolanic reaction of a spent fluid catalytic cracking catalyst in FCC-cement mortars, J. Therm. Anal. Calorim. 90 (2007) 443-447.

[36] L. Soriano, J. Monzó, M. Bonilla, M.M. Tashima, J. Payá, M.V. Borrachero, Effect of pozzolans on the hydration process of Portland cement cured at low temperatures, Cem. Concr. Compos. 42 (2013) 41-48.

[37] B. Pacewska, I. Wilińska, M. Bukowska, Calorimetric investigations of the influence of waste aluminosilicate on the hydration of different cements, J. Therm. Anal. Calorim. 97 (2009) 61-66.

[38] B. Pacewska, I. Wilińska, M. Bukowska, W. Nocún-Wezelik, Effect of waste aluminosilicate material on cement hydration and properties of cement mortars, Cem. Concr. Res. 32 (2002) 1823-1830.

[39] K. Al-Jabri, M. Baawain, R. Taha, Z.S. Al-Kamyani, K. Al-Shamsi, Potential use of FCC spent catalyst as partial replacement of cement or sand in cement mortar, Constr. Build. Mater. 39 (2013) 77-81.

[40] J. Payá, J. Monzó, M.V. Borrachero, S. Velázquez, Cement equivalence factor evaluations for fluid cracking catalyst residue, Cem. Concr. Compos. 39 (2013) $12-17$.

[41] UNE-EN 196-1, Methods of testing cement - Part 1: Determination of strength, 2005.

[42] X.-Y. Wang, Effect of fly ash on properties evolution of cement based materials, Constr. Build. Mater. 69 (2014) 32-40.

[43] J. Payá, M.V. Borrachero, J. Monzó, L. Soriano, Estudio del comportamiento de diversos residuos de catalizadores de craqueo catalítico (FCC) en cemento Portland, Mater. Constr. 59 (2009) 37-52. 